\title{
Dialyzer Blood Leakage
}

National Cancer Institute

\section{Source}

National Cancer Institute. Dialyzer Blood Leakage. NCI Thesaurus. Code C114776.

Leakage of blood into the dialysate during hemodialysis due to apparatus malfunction. 